\title{
Synthesis of Flower-Like Nanoparticles of Anatase Titania by Microwave Solvo-Hydrothermal Method
}

\author{
S. Mahmoudi ${ }^{\dagger}$ and S. Boudjadar \\ Ceramics Laboratory, Department of Physics, University of Constantine, Constantine 25000, Algeria \\ [Manuscript received 17 April 2013, in revised form 15 June 2013] \\ (c) The Chinese Society for Metals and Springer-Verlag Berlin Heidelberg
}

\begin{abstract}
Anatase titania nanoparticles with an average size of about $14 \mathrm{~nm}$ were synthesized by microwave solvothermal method from $\mathrm{TiCl}_{4}$ and ethanol as a precursor and solvent respectively. The shapes of as prepared samples were modified by microwave hydrothermal treatment in strongly alkaline medium at $100{ }^{\circ} \mathrm{C}$ for $2 \mathrm{~h}$, the agglomerate particles can be converted to the nanorods then to flower-like sphere. The structure, morphology and optical properties of as-prepared powders were investigated by X-ray diffraction, scanning electron microscopy and UVvis absorption spectroscopy, the quality of the samples was examined by IR absorption spectroscopy and room temperature photoluminescence $(\mathrm{PL})$. The results showed that the synthesized $\mathrm{TiO}_{2}$ revealed the formation of the nanorods and the flower-like shape of titania after post treatment in $5 \mathrm{~mol} / \mathrm{L}$ and $10 \mathrm{~mol} / \mathrm{L} \mathrm{NaOH}$ solution, respectively. IR absorption spectra showed that the as-prepared $\mathrm{TiO}_{2}$ nanocrystals were highly pure and strongly surface hydrated, The photoluminescence measurement showed that five main emission peaks appeared in UV, violet, blue and green regions.
\end{abstract}

KEY WORDS: Titanium dioxide; Microwave hydrothermal; Alkaline medium; Flowerlike; Photoluminescence

\section{Introduction}

Titania or titanium oxide $\left(\mathrm{TiO}_{2}\right)$ is an attractive semiconducting material due to its characteristic photochemical properties and high chemical stability. $\mathrm{TiO}_{2}$ has been widely used for various applications such as a semiconductor in dye-sensitized solar cell, water treatment materials, catalysts, gas sensors, and so on ${ }^{[1-4]}$. With decrease in particle size of $\mathrm{TiO}_{2}$ to the nanometer scale, the catalytic activity and chemical reactivity are enhanced because the optical band gap is increased due to the quantum size effect, combined with the increased surface area ${ }^{[5,7]}$. Various techniques such as the sol-gel method ${ }^{[8]}$, the chemical vapor decomposition method ${ }^{[9,10]}$ and the hydrothermal technique ${ }^{[11]}$ were used to produce $\mathrm{TiO}_{2}$ nanostructures. The hydrothermal method plays an important role in determination of the microstructures of $\mathrm{TiO}_{2}$. However, the conventional hydrother-

† Corresponding author. Tel.: +213 555153300; E-mail address: Mahmoudisana12@gmail.com (S. Mahmoudi)

DOI: $10.1007 / \mathrm{s} 40195-013-0227-4$ mal method usually needs high pressure, relatively high temperature and long duration for preparation of nanocrystals ${ }^{[12]}$. Microwave hydrothermal $(\mathrm{MH})$ is a recent technique ${ }^{[13,14]}$ to prepare nanocrystalline oxides in very shorter durations. The main advantages of microwave-hydrothermal process over conventional hydrothermal method are, rapid heating to the temperature, extremely rapid kinetics of crystallization, both are expected to lead to energy savings and possible formation of new metastable phases ${ }^{[15,16]}$. We discuss here the effect of alkaline medium post treatment on the crystallite size, morphology and optical proprieties of $\mathrm{TiO}_{2}$ nanoparticles prepared by solvothermal process.

\section{Experimental}

\subsection{Synthesis}

Firstly, in a typical synthesis, $2.9 \mathrm{~mL}$ of $\mathrm{TiCl}_{4}$ $(98 \%)$ was added drop by drop in $50 \mathrm{~mL}$ of ethanol $(96 \%)$ with continuous stirring for $1.5 \mathrm{~h}$ to form a transparent yellowish sol at $0{ }^{\circ} \mathrm{C}$ in an ice-water 
bath, and then the transparent sol was transferred into Teflon-lined autoclave, the autoclave was kept in domestic microwave oven $(2.45 \mathrm{GHz}, 360 \mathrm{~W})$ at $70{ }^{\circ} \mathrm{C}$ for $1 \mathrm{~h}$. after the autoclave was cooled down to room temperature, The white precipitates obtained were first collected by filtration and then washed and dried at $50{ }^{\circ} \mathrm{C}$ for $20 \mathrm{~h}$ in air. The resulting powders were annealed at $400{ }^{\circ} \mathrm{C}$ for $1 \mathrm{~h}$.

In the second step, the samples of $150 \mathrm{mg}$ of $\mathrm{TiO}_{2}$ powders obtained were dispersed respectively in $50 \mathrm{~mL}$ of $1 \mathrm{~mol} / \mathrm{L}, 5 \mathrm{~mol} / \mathrm{L}$ and $10 \mathrm{~mol} / \mathrm{L}$ of $\mathrm{NaOH}$ solutions with magnetic stirring for $15 \mathrm{~min}$, and then the resultant aqueous solutions were transferred to Teflonlined autoclave and maintained in a microwave oven at $100{ }^{\circ} \mathrm{C}$ for $2 \mathrm{~h}$, the operating power is $360 \mathrm{~W}$. The obtained precipitates were washed by distilled water and $\mathrm{HCl}$ acid aqueous solution alternately in the aim to remove residual $\mathrm{Na}$ ions. Finally, the materials were dried at $70^{\circ} \mathrm{C}$ for $1 \mathrm{~h}$ in air and were annealed at $400{ }^{\circ} \mathrm{C}$ for $1 \mathrm{~h}$.

\subsection{Characterization}

The structure and the phase of the resultingnanoparticles were characterized by X-ray diffraction (XRD), using $\mathrm{Cu} K_{\alpha}$ radiation in a BrukerAXS type D8 diffractometer in the range from $20^{\circ}$ to $70^{\circ}$. The morphology and the size distribution of the particles were revealed by an environmental scanning electron microscopy (ESEM, Philips XL 30 FEG). The UV-visible absorption spectra were obtained in the wavelength range from 200 to $800 \mathrm{~nm}$ using a UV-visible spectrophotometer (Shimadzu UV - 2501PC). The composition quality and molecular structure of the synthesized material were characterized, by Fourier transform infrared (FTIR) spectrometer (8201PC, SHIMADZU) in the range from 400 $\mathrm{cm}^{-1}$ to $4000 \mathrm{~cm}^{-1}$ using the $\mathrm{KBr}$ pellet technique. The photoluminescence (PL) of $\mathrm{TiO}_{2}$ powder was investigated at room temperature on Perkin Elmer LS 55 spectrophotometer using $325 \mathrm{~nm}$ Xenon laser as the excitation light source.

\section{Results and Discussion}

\subsection{X-ray diffraction}

The XRD patterns of the as-prepared nanocrystalline $\mathrm{TiO}_{2}$ samples synthesized under different hydrothermal conditions shown in Fig. 1 reveal diffraction peaks of (101), (004), (200), (105) and (211) which are characteristic of the anatase phase. All samples showed a highly crystalline structure and no impurity peaks related to the reactants precursor are detected. The crystallinity of the treated samples increases with increasing $\mathrm{NaOH}$ concentration in aqueous solution. It is obvious that the average crystallite sizes calculated from (101) XRD peak of anatase us-

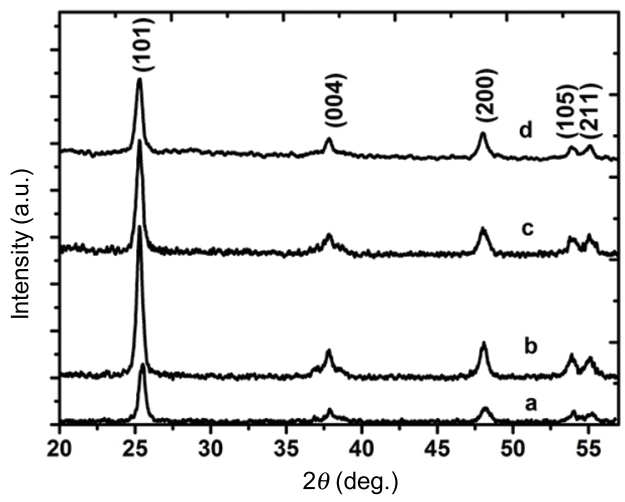

Fig. 1 XRD patterns of nanocrystalline $\mathrm{TiO}_{2}$ prepared by hydrothermal method at different concentrations of $\mathrm{NaOH}$ solution: (a) untreated $\mathrm{TiO}_{2}$, (b) $\mathrm{TiO}_{2}-1 \mathrm{~mol} / \mathrm{L} \mathrm{NaOH}$, (c) $\mathrm{TiO}_{2}-5 \mathrm{~mol} / \mathrm{L}$ $\mathrm{NaOH}$, (d) $\mathrm{TiO}_{2}-10 \mathrm{~mol} / \mathrm{L} \mathrm{NaOH}$

ing Scherrer's equation: $D=0.9 \lambda /(\beta \cos \theta)$, where $\lambda$ is the X-ray wavelength $(\lambda=0.15418 \mathrm{~nm}), \theta$ is the Bragg angle and $\beta$ is the half-height width of the diffraction peak of anatase powder, show no significant variations $(14.56 \mathrm{~nm}-13.64 \mathrm{~nm})$. The distortion of the $\mathrm{TiO}_{2}$ matrices is also estimated from the XRD spectra using the formula: $\varepsilon=\beta / 4 \operatorname{tg} \theta^{[17]}$. Results show that the distortion increases slightly from 20.71 to 22.11 as concentration increasing. The different characteristics of the samples are summarized in Table 1.

\subsection{Morphology analysis}

The morphologies of the resulting samples are investigated by scanning electron microscopy (SEM). Fig. 2 gives the morphologies of as prepared powders. It can be seen from Fig. 2(a) and Fig. 2(b), the samples untreated and post treated in $1 \mathrm{~mol} / \mathrm{L}$ $\mathrm{NaOH}$ aqueous solution respectively appear to be the agglomerated, and the clustered particles. The SEM image of the nanorods resulting from the post treatment in $5 \mathrm{~mol} / \mathrm{L} \mathrm{NaOH}$ aqueous solution is shown in Fig. 2(c). The analysis of this image reveals that the nanorods have an average length ranged between 1 and $9 \mu \mathrm{m}$ and the average diameter ranged between 50 and $600 \mathrm{~nm}$. The small flower-like structure obtained from the post treatment in $10 \mathrm{~mol} / \mathrm{L} \mathrm{NaOH}$ aqueous solution is shown in Fig. 2(d).

\subsection{FT-IR spectra}

IR spectroscopy was used to examine the surface chemical states of the as-prepared samples. The chemical composition of the prepared powders at different concentrations of the $\mathrm{NaOH}$ solution was investigated by FT-IR (Fig. 3). For the as-prepared $\mathrm{TiO}_{2}$ samples, several absorption bands corresponding the vibrational modes of organic species such as hydroxyl, carboxilate and alkane groups are observed. A broad absorption peak at $490 \mathrm{~cm}^{-1}$ wavelength ranges is 
Table 1 The crystallite size, matrix distortion and the band gaps energy of the samples

\begin{tabular}{cccc}
\hline Material & Crystallite size $(\mathrm{nm})$ & Matrix distortion $(\%)$ & Band gap energy $E_{\mathrm{g}}(\mathrm{eV})$ \\
\hline $\mathrm{TiO}_{2}$ & 14.56 & 20.71 & 3.20 \\
$\mathrm{TiO}_{2}-\mathrm{NaOH} 1 \mathrm{~mol} / \mathrm{L}$ & 13.75 & 21.95 & 3.29 \\
$\mathrm{TiO}_{2}-\mathrm{NaOH} 5 \mathrm{~mol} / \mathrm{L}$ & 13.66 & 21.92 & 3.32 \\
$\mathrm{TiO}_{2}-\mathrm{NaOH} 10 \mathrm{~mol} / \mathrm{L}$ & 13.66 & 22.11 & 3.36 \\
\hline
\end{tabular}
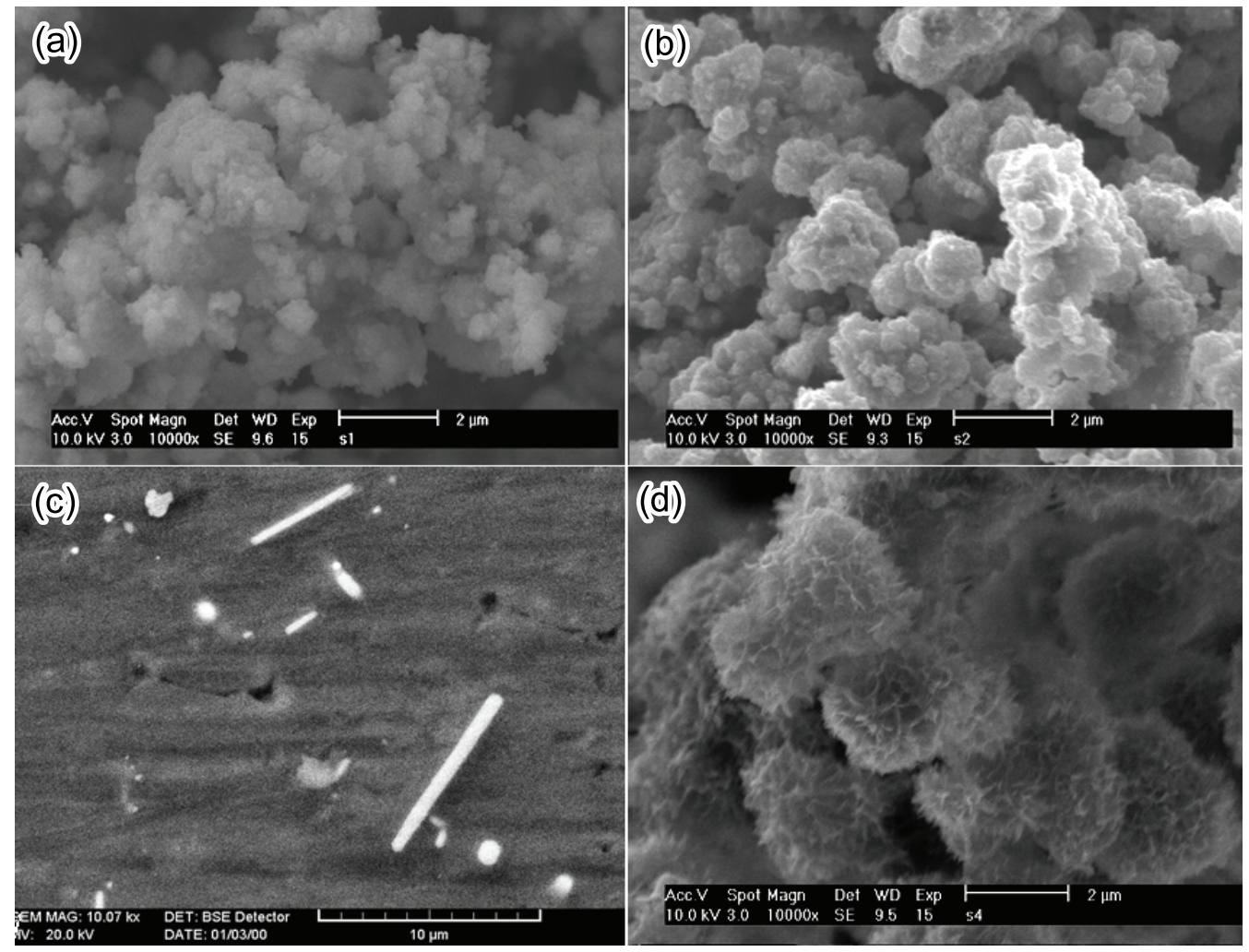

Fig. 2 SEM images of nanocrystalline $\mathrm{TiO}_{2}$ prepared by hydrothermal method at different concentrations of $\mathrm{NaOH}$ solution: (a) untreated $\mathrm{TiO}_{2}$, (b) $\mathrm{TiO}_{2}-1 \mathrm{~mol} / \mathrm{L} \mathrm{NaOH}$, (c) $\mathrm{TiO}_{2}-5 \mathrm{~mol} / \mathrm{L} \mathrm{NaOH}$, (d) $\mathrm{TiO}_{2}-10 \mathrm{~mol} / \mathrm{L} \mathrm{NaOH}$

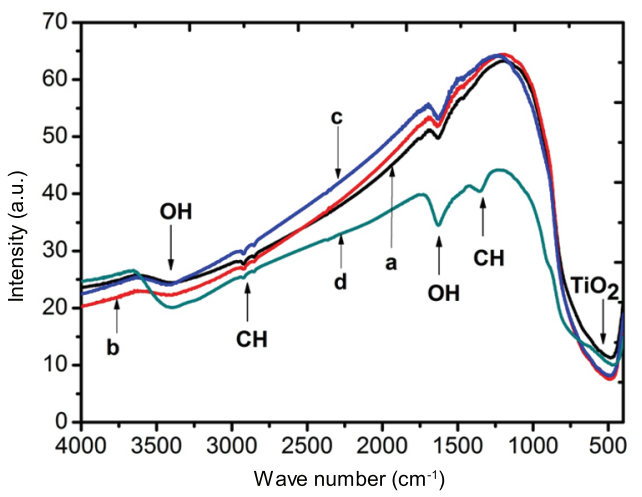

Fig. 3 Infrared spectra of nanocrystalline $\mathrm{TiO}_{2}$ prepared by hydrothermal method at different concentrations of $\mathrm{NaOH}$ solution: (a) untreated $\mathrm{TiO}_{2}$, (b) $\mathrm{TiO}_{2}-1 \mathrm{~mol} / \mathrm{L} \mathrm{NaOH}$, (c) $\mathrm{TiO}_{2}-5 \mathrm{~mol} / \mathrm{L} \mathrm{NaOH}$, (d) $\mathrm{TiO}_{2}-10 \mathrm{~mol} / \mathrm{L} \mathrm{NaOH}$

clearly visible; this is attributed to $\mathrm{Ti}-\mathrm{O}$ stretching and $\mathrm{Ti}-\mathrm{O}-\mathrm{Ti}$ bridging stretching modes ${ }^{[18]}$. A broad band observed in between 3700 and $3000 \mathrm{~cm}^{-1}$ is related to the $\mathrm{O}-\mathrm{H}$ stretching mode of hydroxyl group,
The former absorption is attributed to the hydroxyl groups of $\mathrm{Ti}-\mathrm{OH}$ at weak surface-active sites to which physisorbed water molecules are bound by hydrogen bonds with $\mathrm{OH}$ - groups of $\mathrm{TiO}_{2}$ surfaces ${ }^{[19]}$, The peaks in between 3000 and $2800 \mathrm{~cm}^{-1}$ are assigned to $\mathrm{C}-\mathrm{H}$ stretching vibrations of alkane groups. The very weak absorption observed at $1395 \mathrm{~cm}^{-1}$ is associated with the appearance of carbonate-alike species ${ }^{[20]}$. These results suggest that the as-prepared anatase $\mathrm{TiO}_{2}$ nanocrystals are highly pure and strongly surface hydrated.

\section{$3.4 U V$-visible spectroscopy}

UV-visible spectroscopy was used to investigate the light absorption capacity of the prepared samples. The changes in the absorption spectra of untreated and $\mathrm{M}-\mathrm{NaOH}$ treated solution are shown in Fig. 4. The band gap absorption edges of the dispersed untreated and treated $\mathrm{TiO}_{2}$ particles are ranged between $387.5 \mathrm{~nm}$ and $370 \mathrm{~nm}$. The UV-vis absorption band edge is a strong function of the crystallite size of $\mathrm{TiO}_{2}$ 


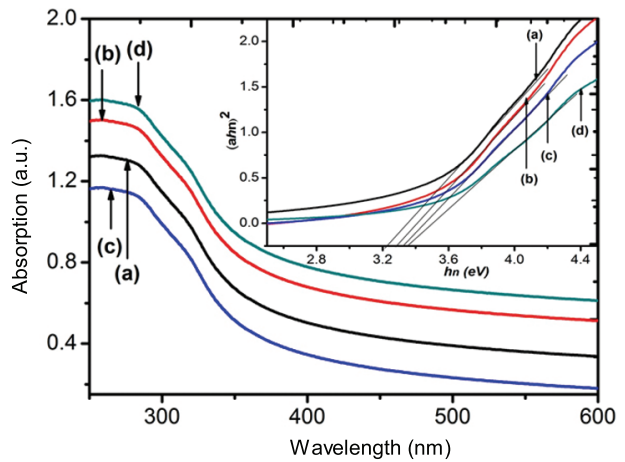

Fig. 4 UV-vis spectra of nanocrystalline $\mathrm{TiO}_{2}$ prepared by hydrothermal method at different concentrations of $\mathrm{NaOH}$ solution: (a) untreated $\mathrm{TiO}_{2}$; (b) $\mathrm{TiO}_{2}-1 \mathrm{~mol} / \mathrm{L} \mathrm{NaOH}$, (c) $\mathrm{TiO}_{2}-5 \mathrm{~mol} / \mathrm{L}$ $\mathrm{NaOH},(\mathrm{d}) \mathrm{TiO}_{2}-10 \mathrm{~mol} / \mathrm{L} \mathrm{NaOH}$

nanoparticles. Usually the band gap between the valance band and the conduction band of the semiconductor increases with the decrease of the particle size. The relationship between the absorption coefficient and the incident photon energy of the semiconductor is given in the following equation ${ }^{[21]}$ :

$$
\alpha h v=\left(h v-E_{\mathrm{g}}\right)^{n}
$$

where $\alpha$ is the absorption coefficient, $h v$ is the energy of the incident photon, $n$ is 0.5 and 2.0 for a direct transition semiconductor and indirect transition semiconductor, respectively.

The $\mathrm{TiO}_{2}$ is the direct semiconductor, which has a very small absorption coefficient. According to this equation, the band gap energy of the dispersed $\mathrm{TiO}_{2}$ particles is measured to be $3.36 \mathrm{eV}$ corresponding $369.04 \mathrm{~nm}$. The corresponding blue shift of $0.16 \mathrm{eV}$ from the $\mathrm{TiO}_{2}$ (no treated) band gap energy $(3.2 \mathrm{eV})$ indicated that the small $\mathrm{TiO}_{2}$ particles were formed.

\subsection{Photoluminescence}

PL emission spectra can be used to investigate the efficiency of charge carrier trapping, immigration and transfer, and to understand the fate of photogenerated electrons and holes in semiconductor since PL emission results from the recombination of free carriers $^{[22,23]}$. Fig. 5 shows the room temperature PL spectra for $\mathrm{TiO}_{2}$ and $\mathrm{TiO}_{2}$ treated by $\mathrm{NaOH}$ solution. Five main emission peaks appear at about $3.24,3.02,284,2.62$ and $2.39 \mathrm{eV}$, which correspond to the $382,410,436,473$ and $518 \mathrm{~nm}$ wavelengths respectively. The five main emission peaks appear in UV, Violet, blue and green regions respectively. The former is ascribed to the emission of band to band transition ${ }^{[23]}$. The latter is the emission signal originated from the charge-transfer transition from $\mathrm{Ti}^{3+}$ to oxygen anionin a $\mathrm{TiO}_{6}{ }^{-8}$ complex ${ }^{[24,25]}$. The

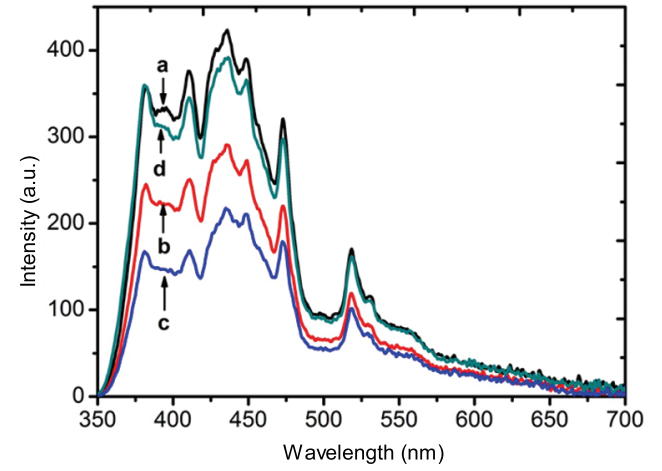

Fig. $5 \mathrm{PL}$ spectra of nanocrystalline $\mathrm{TiO}_{2}$ prepared by hydrothermal method at different concentrations of $\mathrm{NaOH}$ solution: (a) untreated $\mathrm{TiO}_{2}$, (b) $\mathrm{TiO}_{2}-1$ mol/L NaOH, (c) $\mathrm{TiO}_{2}-5 \mathrm{~mol} / \mathrm{L} \mathrm{NaOH}$, (d) $\mathrm{TiO}_{2}-$ $10 \mathrm{~mol} / \mathrm{L} \mathrm{NaOH}$

difference of about $0.85 \mathrm{eV}$ between the band gap energy $(3.19 \mathrm{eV})$ and the emission peak energy (2.39 $\mathrm{eV}$ ) is caused by the Stokes shift due to the FranckCondon effect ${ }^{[22-26]}$. The variation of PL intensity may result from the change of defect states on the shallow level of nanopowders crystallites ${ }^{[27,28]}$. Therefore, a lower PL intensity might show a lower recombination rate of hotogenerated electrons and holes on the shallow level of nanopowders under light irradiation. It can be seen from Fig. 5 that the PL intensity decreased with increasing the concentration of $\mathrm{NaOH}$ solution. At $10 \mathrm{~mol} / \mathrm{L} \mathrm{NaOH}$ the PL intensity reached its higher value. The increase of PL intensity could be described to the introduction of new defect sites in the sample.

\section{Conclusions}

$\mathrm{TiO}_{2}$ nanorods and flower-like shape were successfully synthesized by microwave solvo-hydrothermal method. The crystallite size revealed by XRD analysis showed no significant variations $(14.56-13.64 \mathrm{~nm})$ with increasing $\mathrm{NaOH}$ concentration. The observation of as-synthesized product revealed the formation of the nanorods and the flower-like shape of titania with $5 \mathrm{~mol} / \mathrm{L}$ and $10 \mathrm{~mol} / \mathrm{L} \mathrm{NaOH}$ solution, respectively. IR absorption spectra showed that the asprepared anatase $\mathrm{TiO}_{2}$ nanocrystals were highly pure and strongly surface hydrated. The revealed photoluminescence measurement showed that five main emission peaks appeared in UV, violet, blue and green regions.

\section{REFERENCES}

[1] A. Hagfeldt and M. Gratzel, Chem. Rev. 95 (1995) 49.

[2] S. Sakthivel and H. Kisch, Angew. Chem. Int. Ed. 42 (2003) 4908.

[3] R.K. Sharma, M.C. Bhatnagar and G.L. Sharma, Sens. Actuat. B Chem. 46 (1998) 194. 
[4] K. Luchi, Y. Ohko, T. Tatsuma and A. Fujishima, Chem. Mater. 16 (2004) 1165.

[5] A. Mills and S. Le Hunte, J. Photochem. Photobiol. A Chem. 108 (1997) 1.

[6] J. Aguado, R. van Grieken, M.J. Lopez-Munoz and J. marugan, Catal. Today. 75 (2002) 95.

[7] K.M. Reddy, C.V.G. Reddy and S.V. Manorama, J. Solid State Chem. 158 (2001) 180.

[8] B. Samuneva, V. Kozhukharqv, C. Trapalis and R. Kranold, J. Mater. Sci. 28 (1993) 2353.

[9] K.S. Mazdiyasni, C.T. Lynch and J.S. Smith, J. Am. Ceram. Soc. 48 (1965) 372

[10] Y. Qian, Q. Chen, Z. Chen, C. Fan and G. Zhou, J. Mater. Chem. 3 (1993) 203.

[11] H. Cheng, J. Ma and L. Qi, Chem. Mater. 7 (1995) 663.

[12] S. Ito, T.N. Murakami, P. Comte, P. Liska, C. Gratzel, M.K. Nazeeruddin and M. Gratzel, Thin Solid Films 516 (2008) 4613.

[13] Y.V. Kolen'ko, V.D. Maximov, A.V. Garshev, P.E. Meskin, N.N. Oleynikov, and B.R. Churagulov, Chem. Phys. Lett. 388 (2004) 411.

[14] J.G. Yu, G.H. Wang, B. Cheng and M.H. Zhou, Appl. Catal. B: Environ. 69 (2007) 171.

[15] S. Cho, D.S. Shim, S.H. Jung, E. Oh, B.R. Lee and K.H. Lee, Mater. Lett. 63 (2009) 739.
[16] T. Thongtem, A. Phuruangrat and S. Thongtem, Ceramics Int. 36 (2010) 257.

[17] J.W. Shi, J.T. Zheng, Y. Hu and Y.C. Zhao, Mater. Chem. Phys. 106 (2007) 247.

[18] A.M. Peiro, J. Peral, C. Domingo, X. Momenech and J.A. Ayllon, Chem. Mater. 13 (2001) 2567.

[19] T. Bezrodna, G. Puchkovska, V. Shimanovska, I. Chashecnikova, T. Khalyavka and J. Baran, Appl. Surf. Sci. 214 (2003) 222.

[20] G.S. Li, L.P. Li, J. Boerio-Goates and B.F. Woodfield, J. Am. Chem. Soc. 127 (2005) 8659.

[21] B. Oregan and M. Gratzel, Nature 353 (1991) 737.

[22] J.G. Yu, H.G. Yu, C.H. Ao, S.C. Lee, J.C. Yu and W.K. Ho, Thin Solid Films 496 (2006) 273.

[23] F.B. Li and X.Z. Li, Appl. Catal. A Gen. 228 (2002) 15.

[24] K. Fujihara, S. Izumi, T. Ohno and M. Matsumura, J. Photochem. Photobiol. A Chem. 132 (2000) 99.

[25] N. Serpone, D. Lawless and R. Khairutdinov, J. Phys. Chem. 99 (1995) 16646.

[26] F.B. Li and X.Z. Li, Appl. Catal. A Gen. 228 (2002) 15.

[27] T. Toyoda, T. Hayakawa, K. Abe, T. Shigenari and Q. Shen, J. Lumin. 87-89 (2000) 1237.

[28] D. Huang, S. Liao, J. Liu, Z. Dang and L. Petrik, J. Photochem. Photobiol. A 184 (2006) 282. 